\title{
USE OF MSC.ADAMS SOFTWARE PRODUCT IN MODELLING VIBRATION SOURCES
}

This paper presents the methodology of rotating device modelling in order to facilitate correct evaluation of selected, usually malfunction (degraded) states of rotating machines of mechanical systems, especially of gearboxes. The analysis was performed using mathematical models utilising MSC.ADAMS software product to solve the dynamics of a system of bodies. The correctness of the proposed method is verified by qualitative comparison of simulation results with the presented symptoms of malfunction states and also by comparison with real measurement results from technical practice.

Keywords: Dynamics, rotating machine, gear mesh frequency, frequency spectrum, MSC.ADAMS.

\section{Introduction}

Correct operation of machinery inevitably requires alignment of machine geometry in hundredths of millimetres (depending on the shaft speed). Shaft misalignment results in increased reactions, which the bearings must absorb, it induces mechanical looseness, damages to seals, allows fluids and impurities to enter the bearings, which considerably decreases the machine operating life and, consequently, the operating life of the whole machinery. Carrying out purposeful maintenance of machines requires a correct interpretation of malfunction causes. Very frequent claims are that malfunction is caused by the bearing, seals or others. However, these are the consequences and not the initial causes of malfunction. In general, there is a lack of correlation between causes and consequences of malfunctions [1].

One of non-destructive methods allowing identifying and consequently eliminating the problem is vibration diagnostics of rotating machinery. It uses vibrations, which are generated by machines in operation, as a source of information about the way of its working. Vibration diagnostics is also an important tool of modern productive and proactive methods of machinery maintenance. Using this tool, maintenance of machines is planned according to the actual state, and, therefore, many useless preventive revisions are eliminated, which leads to important savings of spare parts and time for machinery repair. It gives information about regularly monitored machines, by which we can prolong the planned periods of shutdowns or prepare in advance for the repair of specific monitored machine node etc. [2, 3, 4 and 5].

However, the above is diagnostics of malfunction caused by experimental method right in the operation. In the recent decades many software products solving dynamic problems of rotating machines were developed, therefore, computer simulation and building of virtual prototypes (VP) is nowadays an essential part of every technical solution [6]. Often, there is a question how to create a VP so that the results of its mathematical solution correspond to physical values or values acquired by experimental measurement.

The paper presents the creation of a virtual prototype of gearing, and this prototype is used to generate and analyse dynamic effects measurable in the place of rotary links between the shaft and the frame. These effects are registered as vibration velocity. We then use the generated courses of vibration velocity to obtain velocity spectrum, and this spectrum will be compared with the spectra from diagnostic measurements. In this way we can verify the created virtual model, adjust its appropriate variables to select a suitable solver in MSC.ADAMS software.

\section{Manifestations of the gearbox normal spectrum}

The gearbox normal spectrum (gearbox without damage) is characterised by the presence of revolution frequencies of the two shafts $f_{1}, f_{2}$ (with gear wheels $t_{1}, t_{2}$ ) and tooth frequency (including

\footnotetext{
* Alzbeta Sapietova, Vladimir Dekys

Department of Applied Mechanics, Faculty of Mechanical Engineering, University of Zilina, Slovakia,

E-mail: alzbeta.sapietova@fstroj.uniza.sk
} 
its higher harmonics). Using the distance of the sideband $\Delta \mathrm{f}$ we can determine the source responsible for generating the tooth frequency (Fig. 1). However, sidebands are usually not pronounced. Normal speed spectrum is usually characterised by the following peaks (Fig. 1) [1 and 7]:

- revolution frequency of individual shafts,

- generating the tooth frequency $\mathrm{f}_{\mathrm{GMF}}=\mathrm{f}_{1} \cdot \mathrm{t}_{1}=\mathrm{f}_{2} \cdot \mathrm{t}_{2}$ and its multiples $2 \mathrm{xf}_{\mathrm{GMF}}, 3 \mathrm{xf}_{\mathrm{GMF}}$ with sidebands. Sidebands may not be significantly pronounced and their distance from the tooth frequency (and its harmonics) very often coincides with the revolution frequency of one of the shafts,

- however, tooth frequencies and their multiples are not significant, often their amplitude decreases with increasing multiple of revolution frequency, and eigenfrequency of one of the wheels does not appear in the spectrum.

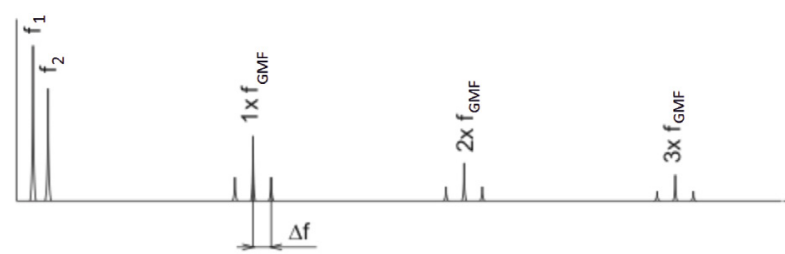

Fig. 1 Normal spectrum of the gearbox, $\Delta f$ is the sideband distance.

It should be noted that the term "normal spectrum" is hereby incorporated in an intuitive sense [8 and 9]. Normal spectrum corresponds to a state where the object performs required functions, even if it features ongoing degradation processes that usually generate other peaks in the spectrum. The term "normal spectrum" is then equated to a descriptive expression "time-stable nature of spectrum (often determined using periodically repeated measurements), with peak levels not exceeding certain limits".

\section{Modelling a spur gearing}

We used the MSC.Adams/View software environment to create a VP (Fig. 2) for modelling and error analysis of the gear transmission mechanism. The VP consists of solid bodies, the shaft is modelled by a geometric element "cylinder" and the spur gearing is imported from the 3D parametric modelling software, Pro Engineer.

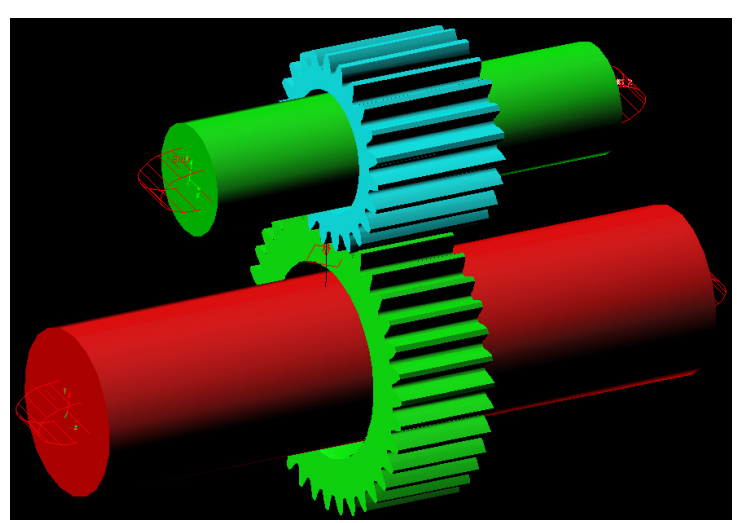

Fig. 2 Spur gearing virtual prototype in MSC. ADAMS

\section{Shaft mounting on a bushing elastic fastener}

The gearing VP was attached to the frame in the MSC. ADAMS environment using a bushing force bond, which is force based connections of members. The advantage of this link is the fact that it can simulate the system elasticity (flexibility). It allows connection of two bodies. Bushing has 6 force degrees of freedom. Three forces and three moments act in the axes of the link coordinate system. The software calculates components of forces and moments. In general, the bushing properties are defined by six stiffness coefficients, six damping coefficients and optional prestress condition. Instead of the prestress value the initial conditions can be defined also by initial displacement [10].

It follows from the above that between two bodies linked by bushing, there are applied three forces: $F_{x}, F_{y}$ and $F_{z}$, and three moments: $\mathrm{T}_{\mathrm{x}}, \mathrm{T}_{\mathrm{y}}$ and $\mathrm{T}_{\mathrm{z}}$, acting in the axes of a rectangular Cartesian coordinate system. These are a linear function of translational and rotational movement between the two coordinate systems of these bodies.

The general mathematical formulation of the bushing force element is [10]:

$$
\begin{aligned}
& {\left[\begin{array}{c}
F_{X} \\
F_{y} \\
F_{Z} \\
T_{X} \\
T_{Y} \\
T_{Z}
\end{array}\right]=-\left[\begin{array}{cccccc}
k_{11} & 0 & 0 & 0 & 0 & 0 \\
0 & k_{22} & 0 & 0 & 0 & 0 \\
0 & 0 & k_{33} & 0 & 0 & 0 \\
0 & 0 & 0 & k_{44} & 0 & 0 \\
0 & 0 & 0 & 0 & k_{55} & 0 \\
0 & 0 & 0 & 0 & 0 & k_{66}
\end{array}\right] \cdot\left[\begin{array}{c}
x \\
y \\
z \\
\alpha \\
\beta \\
\gamma
\end{array}\right]-} \\
& -\left[\begin{array}{cccccc}
c_{11} & 0 & 0 & 0 & 0 & 0 \\
0 & c_{22} & 0 & 0 & 0 & 0 \\
0 & 0 & c_{33} & 0 & 0 & 0 \\
0 & 0 & 0 & c_{44} & 0 & 0 \\
0 & 0 & 0 & 0 & c_{55} & 0 \\
0 & 0 & 0 & 0 & 0 & c_{66}
\end{array}\right] \cdot\left[\begin{array}{c}
\dot{x} \\
\dot{y} \\
\dot{z} \\
\dot{\alpha} \\
\dot{\beta} \\
\dot{\gamma}
\end{array}\right]+\left[\begin{array}{c}
F_{X 0} \\
F_{y 0} \\
F_{Z 0} \\
T_{X 0} \\
T_{Y 0} \\
T_{\mathrm{Z} 0}
\end{array}\right]
\end{aligned}
$$


where:

$F_{x}, F_{v}$ and $F_{z}$ are the moving forces in the coordinate system of the J marker,

$x, y$ and $z$ are the bushing deformation vector components in the coordinate system of the $\mathrm{J}$ marker,

$\dot{x}, \dot{y}, a \dot{z}$, is the deformation vector derivation by time, i.e. velocity of displacements,

$F_{x 0^{\prime}} F_{y 0}$ and $\mathrm{F}_{z 0},\left(\mathrm{~T}_{x 0^{\prime}}, T_{y 0}\right.$ and $\left.T_{z 0}\right)$, are the values of constant prestress components of forces (moments) in the coordinate system of the $\mathrm{J}$ marker,

$T_{x}, T_{v}$ and $T_{z}$ are the moments of forces in the coordinate system of the J marker,

$\alpha, \beta$, and $\gamma$ are the small rotation angles of the I marker against the J marker,

$\dot{\alpha}, \dot{\beta}, a \dot{\gamma}$ are the values of angular velocities of the I marker coordinate system expressed in the coordinate system of the $\mathrm{J}$ marker,

$k_{11}-k_{66}$ are the values of stiffness,

$c_{11}-c_{66}$ are the values of damping.

Bushing applies to the balance of the forces and moments of the I marker to the $\mathrm{J}$ marker as follows:

$\mathbf{F}_{j}=-\mathbf{F}_{i}$,

$\mathbf{T}_{j}=-\mathbf{T}_{i}-\delta \times \mathbf{F}_{i}$,

where $\boldsymbol{\delta}$ is the instantaneous deformation vector between the markers from $\mathbf{J}$ to $\mathbf{I}$. While the force applied to the $\mathbf{J}$ marker is equal and oppositely oriented to the force applied on the I marker, the torque in the $\mathrm{J}$ marker is usually not equal to the torque in the I marker, because the moment arm is a function of the bushing element deformation, which can be different in connected bodies [11].

Based on the actual (real) mounting, the shaft is mounted in two bushings, where on one side the axial parameter values are zeroed (axially free), thereby achieving the effect of a possible axial displacement in the mounting.

\section{Force link in the gearing}

The type of link used in the gearing is persisting contact. This force link is represented by a model in the form of a nonlinear spring-damper system, in which the stiffness takes into account the elasticity of contacting surfaces and damping reflects energy dissipation, where the bodies are not separated after colliding [12]. The calculation of contact forces is carried out separately for each point, and the resulting effect is their sum. Reaction forces generated by contact during simulation are an important aspect for assessing the behaviour of the gear transmission. Theoretically, the forces in the contact of the teeth in engagement should have a common bearer lying on a joint tangent of root circles (Fig. 3). However, the lines of action of these reactions in the VP work cycle are often not identical (Fig. 4). It should be noted that that the reactions are generated by the contact function, and, therefore, correct adjustment of the contact is important. The goal is to achieve the effect when the gear wheel surfaces roll away perfectly upon each other, which increases the VP's ability to react to smaller irregularities in the surface geometry.

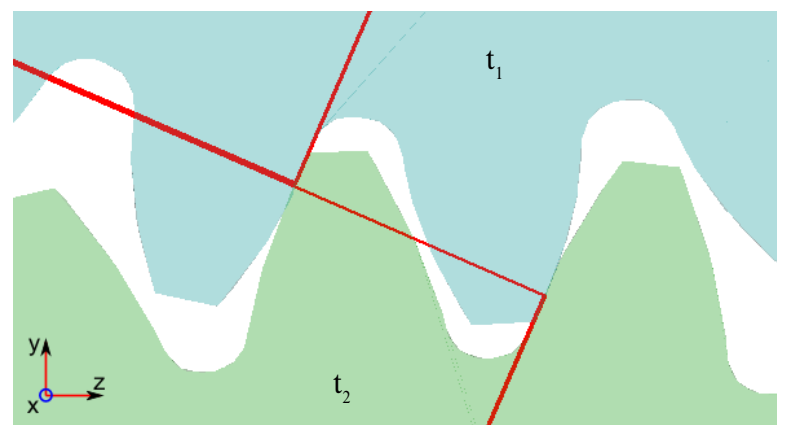

Fig. 3 The lines of action of reactions in the gearing - the ideal state

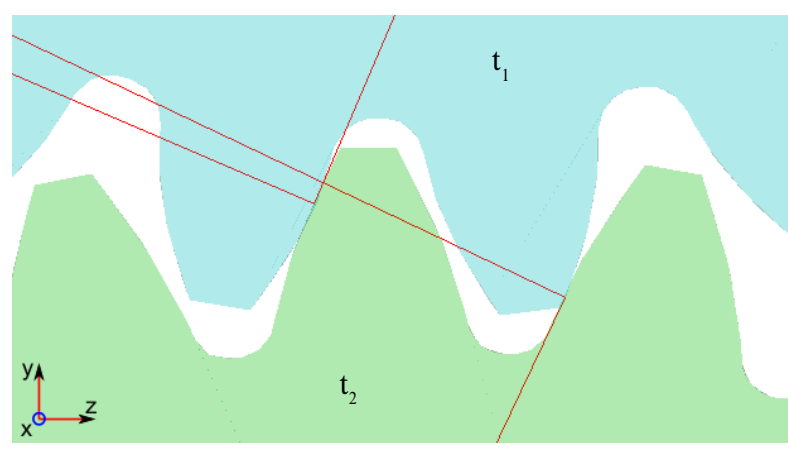

Fig. 4 The lines of action of reactions in the gearing - the lines of action do not overlap

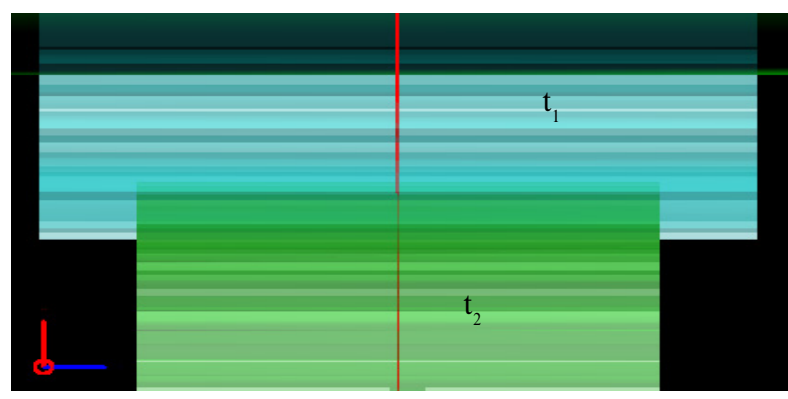

Fig. 5 Side view of the VP, reactions in the monitoring of their perpendicularity to the axis of rotation, reaction effects (red straight

line), reactions lie on one bearer

When observing the contact forces between the tooth system (gearing), it is further necessary to ensure their compliance with perpendicularity to the axis of rotation. Otherwise, misalignment of the shafts is present in the frequency spectrum. Then we 
can talk about a possible misalignment caused by incorrect setting of bushings. Figure 5 shows an illustrative example of an approximately ideal state. If an angle is formed between reactions, then it is appropriate to debug the VP using one of the sensitivity or optimisation analyses (DS/DOE/DO) of MSC. ADAMS software [13 and 14].

\section{Input parameters}

For the VP of spur gearing we determined the following parameters and dependencies:

- The number of teeth is predetermined by this device's geometry and configuration, this will be the key parameter for detecting tooth frequencies and transmission ratio: $\mathrm{t}_{1}=23, \mathrm{t}_{2}$ $=36$.

- Input revolution frequency $\mathrm{f}_{\mathrm{in}}=25 \mathrm{~Hz}$, derived from the value of input revolutions $1500 \mathrm{rpm}$. This will be the key parameter for detecting tooth frequencies.

- Output revolution frequency $\mathrm{f}_{\text {out }}$ is derived based on the input revolution frequency and the transmission ratio $f_{\text {out }}=f_{\text {in }} \cdot t_{1} / t_{2}=$ $15.9 \mathrm{~Hz}$.

- Input angular velocity $\omega_{1}$ is a parameter derived from the input revolutions. Transients were removed using the function STEP (step(time, 0, 0, 1, 157)), thus defining a smooth start and subsequent maintaining of the angular velocity at a constant value.

$\omega_{1}=2 \pi \mathrm{f}=2 \cdot 3.14 \cdot 25=157 \mathrm{rad} / \mathrm{sec}=9000 \mathrm{deg} / \mathrm{sec}$,

angular velocity of the shaft of the output gear wheel is then $\omega_{2}=5750 \mathrm{deg} / \mathrm{sec}$.

- The tooth frequency $\mathrm{f}_{\mathrm{GMF}}$ corresponding to the pair of wheels is dependent on the revolution frequencies of corresponding shafts and wheels mounted to them.

- The pair of wheels will generate the first tooth frequency $1 \mathrm{xf}_{\mathrm{GMF}}=23 \cdot \mathrm{f}_{\text {in }}=36 \cdot \mathrm{f}_{\text {out }}=575 \mathrm{~Hz}$ and other harmonic multiples $2 \mathrm{xf}_{\mathrm{GMF}}, 3 \mathrm{xf}_{\mathrm{GMF}}, 4 \mathrm{xf}_{\mathrm{GMF}}$.

- Simulation parameters: simulation time $-5 \mathrm{~s}$, simulation time step $-0.0005 \mathrm{~s}$, solver type Newmark - it works better than the standard default Gauss solver when using force links and small time steps,

- Parameters of contact between the wheels remained almost the same, except for stiffness $1.10^{7}[\mathrm{~N} / \mathrm{mm}]$ and penetration depth $1.10^{-3}[\mathrm{~mm}]$ in order to achieve a minimum overlap of geometry of teeth in engagement and thus increased surface sensitivity to small changes (damage).

\section{Sensitivity analysis of mounting parameters in bushing links}

In this section we present sensitivity analysis to determine optimal parameters of stiffness $\mathrm{K}$ and damping $\mathrm{C}$ in bushing links.
First, we used the Design Study (DS) method based on a change in the stiffness parameter $\mathrm{K}$ in bushing links to monitor the size of constant angular velocity of the output shaft $\omega_{2}$ It should be understood that DS solving was adjusted to finding an effective value of $\omega_{2}$ (RMS). RMS values were determined only from the revolution-stable time section in post-processing.

Damping was set to a constant value $\mathrm{C}=1 \times 10^{3}[\mathrm{Ns} / \mathrm{mm}]$. It follows from the solution in Table 1 that stiffness $\mathrm{K}$ has a minor effect on the course of the output angular velocity $\omega_{2}$ at constant damping C. For this reason we carried out advanced analysis using the Design of Experiment (DOE) method of searching for effective combinations of parameters $\mathrm{C}$ and $\mathrm{K}$ [15].

DS sensitivity analysis for stiffness parameter $\mathrm{K}$ for target $\omega_{2}=5750 \mathrm{deg} / \mathrm{s}$

Table 1

\begin{tabular}{|c|c|c|}
\hline trial & achieved $\omega_{2}[\mathrm{deg} / \mathrm{s}]$ & stiffness $\mathrm{K}[\mathrm{N} / \mathrm{mm}]$ \\
\hline 1. & 611.1 & $1.10^{3}$ \\
\hline 2. & 4231.3 & $1.10^{4}$ \\
\hline 3. & 5767.1 & $1.10^{5}$ \\
\hline 4. & 5757.9 & $1.10^{6}$ \\
\hline 5. & 5756.8 & $1.10^{7}$ \\
\hline 6. & 5771.7 & $1.10^{8}$ \\
\hline 7. & 5769.1 & $1.10^{9}$ \\
\hline
\end{tabular}

Table 2 shows several selected, more significant combinations achieved within the DOE method solving, i.e. mapping the effective combinations of parameters $\mathrm{K}$ and $\mathrm{C}$ (the values in the table are RMS from the stabilised part of the courses after $2.5 \mathrm{~s}$, i.e. after the transient aftermath). Of the total 49 combinations, trial No. 17 has the RMS value closest to the target value of $\omega_{2}$, both in the value as well as in the quality of the course.

DOE method for input variables $\mathrm{K}$ and $\mathrm{C}$,

and for target value of $\omega_{2}$

Table 2

\begin{tabular}{|c|c|c|c|}
\hline trial & $\begin{array}{c}\text { achieved } \omega_{2} \\
{[\mathrm{deg} / \mathrm{s}]}\end{array}$ & $\begin{array}{c}\text { stiffness K } \\
{[\mathrm{N} / \mathrm{mm}]}\end{array}$ & $\begin{array}{c}\text { damping C } \\
{[\mathrm{Ns} / \mathrm{mm}]}\end{array}$ \\
\hline 4. & 5756.7 & 1.10 & 1.107 \\
\hline 5. & 5757.9 & 1.10 & 1.106 \\
\hline 17. & 5751.1 & 1.103 & 1.105 \\
\hline 18. & 5756.6 & $1.10^{3}$ & $1.10^{6}$ \\
\hline 25. & 5754.6 & $1.10^{4}$ & $1.10^{6}$ \\
\hline 32. & 5753.9 & $1.10^{5}$ & $1.10^{6}$ \\
\hline 39. & 5755.2 & $1.10^{6}$ & $1.10^{6}$ \\
\hline 46 & 5754.2 & $1.10^{7}$ & $1.10^{6}$ \\
\hline 49 & 5756.8 & $1.10^{7}$ & $1.10^{9}$ \\
\hline
\end{tabular}

Monitoring the velocity on the system output included also monitoring the frequency spectra of the tooth frequency. Since this evaluation requires to be carried out by the solver itself, we 
can present in this case that high damping causes suppression of amplitudes in the frequency spectrum.

\section{Monitored parameters}

The state of the evaluated transmission system can be determined by observing the properties that are specific for this system configuration. These specific properties are time and frequency spectra of vibration velocities obtained from the time courses of vibration on the shaft bearing housings. Figure 6 shows the course of velocities on the output bearing observed in radial directions Y (vertical) and Z (horizontal). Figure 7 shows a detail of the course of these velocities from the stable part of the spectrum.

Figure 8 shows the FFT (fast Fourier transform) frequency spectrum corresponding to the above presented course of velocities in the radial direction $\mathrm{Z}$. The course shows a dominant first tooth frequency. The spectrum also includes its harmonic multiples with insignificant sidebands.

\section{Practical example of normal spectrum}

Figure 9 shows a normal spectrum of vibration velocity on the output shaft of a 3-speed gearbox of a cement mill. The spectrum

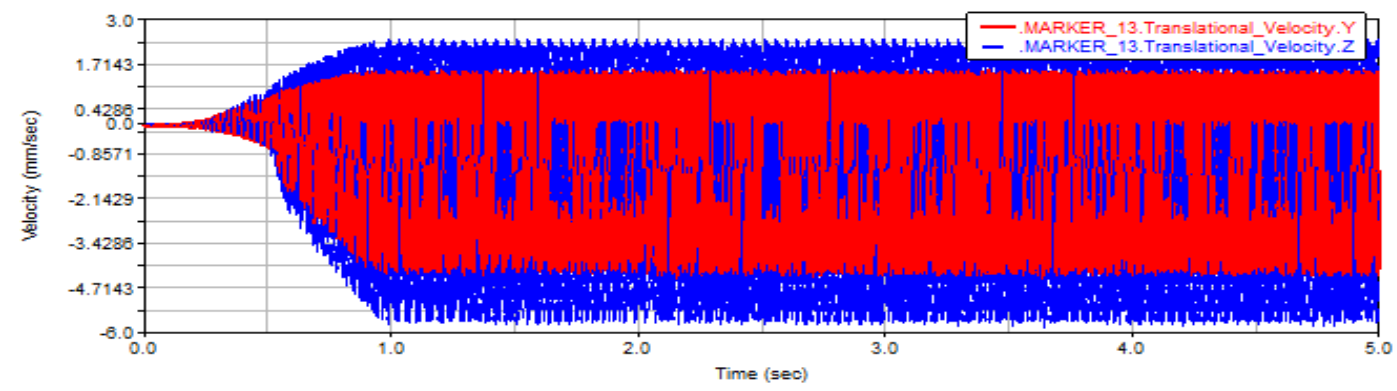

Fig. 6 Velocities in the radial direction on the output bearing

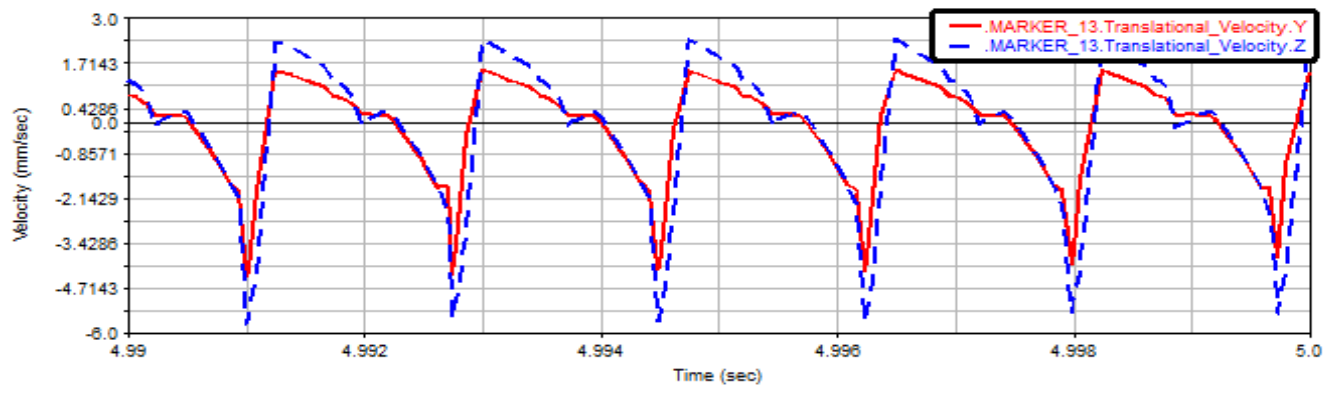

Fig. 7 Detail of velocity in the radial direction on the output bearing

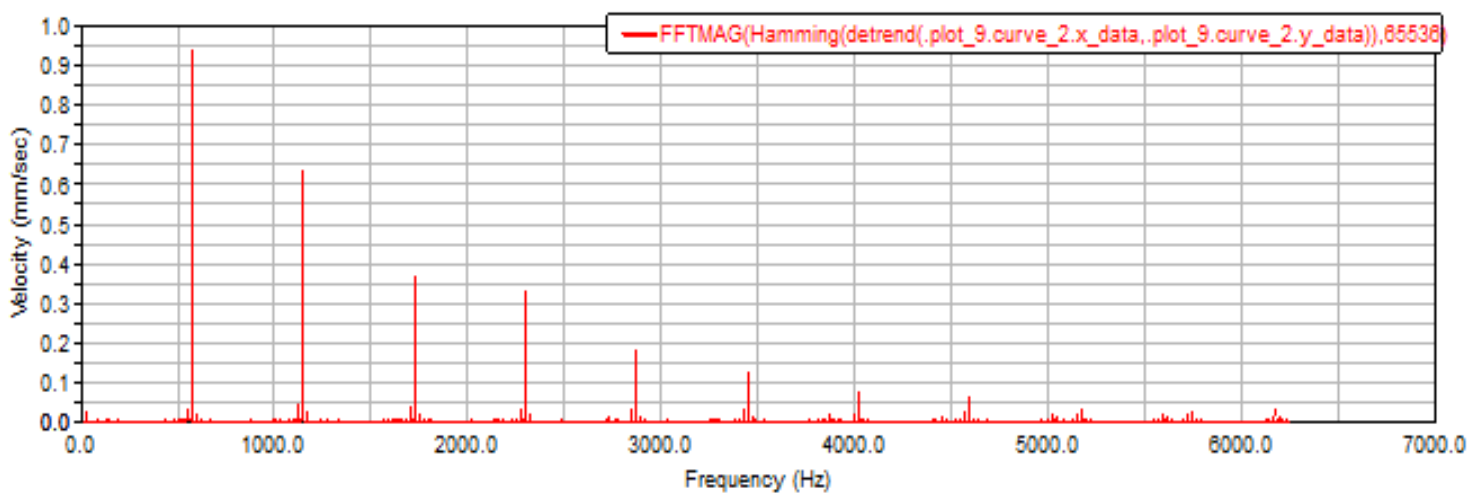

Fig. 8 FFT velocities in the radial direction on the output bearing 


\section{COMMNICOIIONS}

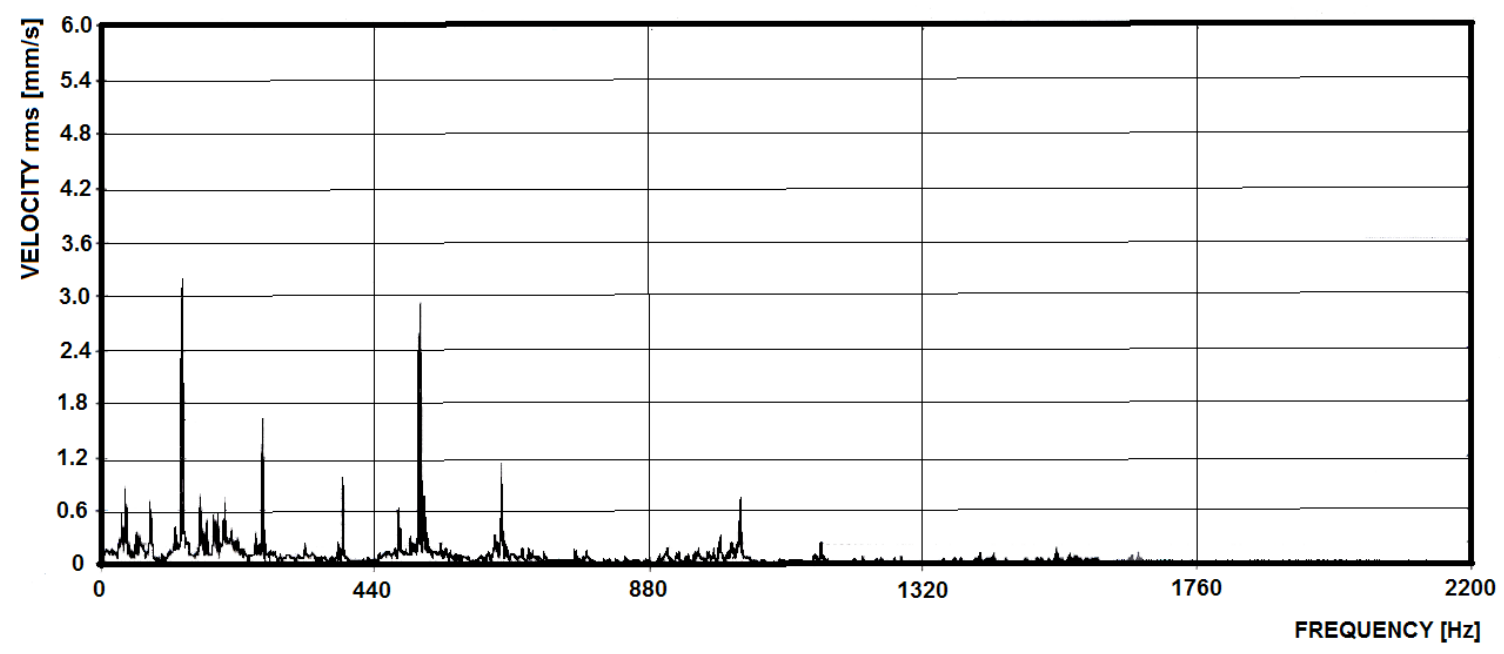

Fig. 9 Normal FFT spectrum of a raw mill gearbox, characterised by decrease in higher multiples of tooth frequencies

includes lower, but significant multiples of $\mathrm{f}_{\mathrm{GMF} 3}(40.4 \mathrm{~Hz}, 120 \mathrm{~Hz}$, $160.4 \mathrm{~Hz}$, output gear), two dominant peaks at multiples of $\mathrm{f}_{\mathrm{GMF} 2}(130.4 \mathrm{~Hz}, 259.7 \mathrm{~Hz})$, and significant multiples of the tooth frequency $\mathrm{f}_{\mathrm{GMF} 1}(513.3 \mathrm{~Hz}$ and $1026.6 \mathrm{~Hz}$, input gear). This measurement clearly shows a decrease of amplitudes of harmonic tooth frequencies for individual gear speeds.

\section{Conclusion}

The presented methodology of modelling a system of gear wheels seems satisfactory, since the expected results were achieved in both time spectrum (Fig. 6) and frequency spectrum (Fig. 7).

When modelling a system of gear wheels it is necessary to achieve that tooth surfaces perfectly roll away over each other, which increases the virtual prototype sensitivity to minor surface imperfections. This means we need to employ sensitivity analysis to correctly set both the lines of action of reactions of contact in the gearing and also optimal parameters of stiffness and damping in the links. The shaft is mounted in two bushing-type links - one of them has zero axial values of the parameters, thereby achieving the effect of a possible axial displacement in the shaft mounting. Parameters of contact between the gearing remained almost constant, except for stiffness $1 \times 10^{7}[\mathrm{~N} / \mathrm{mm}]$ and penetration depth $1 \times 10^{-3}[\mathrm{~mm}]$ (achieved minimal overlap of geometries) [16 - 17].

In the created VP, the courses of kinematic parameters and FFT spectra were qualitatively identical to the predicted and practically measured ones. This created VP of a gearing may further serve to modelling failure states in the gearing, such as misalignment, damage to teeth, etc. This will allow analysing and mutually comparing, for example, the manifestations of undamaged and damaged gearboxes.

\section{Acknowledgement}

This work was supported by the Slovak Research and Development Agency under the contract No. APVV-0736-12 and the Slovak Grant Agency VEGA 1/0983/15.

\section{References}

[1] BILOSOVA, A., BILOS, J.: Vibration Diagnostics (in Czech), Ostrava, 2012.

[2] KREIDL, M., SMID, R.: Technical Diagnostics (in Slovak), BEN: Praha 2006, ISBN 80-73000-158-6.

[3] KREIDL, M., et al.: Diagnostic Systems (in Czech), CVUT: Praha 2001, ISBN 80-01-02349-4.

[4] SHEFFER, D., GIRHARD, T.: Practical Machinery Vibration Analysis and Predictive [

[5] BAKOWSKI, A., RADZISZEWSKI, L., ZMINDAK, M.: Analysis of Uncertainty in Pressure Measurement with a Piezoelectric Transducer for a Combustion Engine. Applied Mechanics and Materials, vol. 827, 2015, pp. 77-82.

[6] VAVRO, J., VAVRO, J., jr., VAVROVA, A., KOVACIKOVA, P.: Dynamic Analysis of Winding Mechanisms for Manufacturing of Raw Tyres. Hutnicke listy, No. 64, pp.189-192. 
[7] DEKYS, V., NOVAK, P.: Report: Condition Monitoring of Bearings in Test Laboratory PSL. University of Zilina: SjF: Department of Applied Mechanics, No. 1, June 2005.

[8] BERRY, J., E.: Intensive Vibration Diagnostics. SKF Condition Monitoring, Zaltbommel, June 1985, Intensive condition monitoring course: Technical Associates: Charlotte, 1985.

[9] ADAMS, M., L.: Rotating Machinery Vibration from Analysis to Troubleshooting, New York: Marcel Dekker, 2001, ISBN 0-82470258-1.

[10] KIVINIEMI, T., HOLOPAINEN, T.: Modelling of Flexible Members for Simulation of Vehicle Dynamics [online], 1999, [cit. 201504-07], http://www.vtt.fi/inf/julkaisut/muut/ 1990s/valb 424.pdf.

[11] KOPAS, P., VASKO, M., HANDRIK, M.: Computational Modeling of the Microplasticization State in the Nodular Cast Iron. Applied Mechanics and Materials, 2014, vol. 474, pp. 285-290, ISSN 16609336.

[12] HYBEN, B., SAPIETA, M.: Multi-software Solution of Optimization for Selected Parameters Machinery in Terms of their Mechanical Properties. Computational mechanics 2012, Pilsen: University of West Bohemia, 2012. ISBN 978-80-261-0157-4 - CD-ROM, [2] s.

[13] SAGA, M., KOPAS P., VASKO, M.: Some Computational Aspects of Vehicle Shell Frames Optimization Subjected to Fatigue Life. Communications - Scientific Letters of the University of Zilina, vol. 12, No. 4, 2010, pp. 73-79.

[14] SAPIETOVA, A., SAPIETA, M., HYBEN, B.: Sensitivity Analysis Application for Multibody System Synthesis. Applied Mechanics and Materials, vol. 420, 2013, pp. 68-73, Online available since 2013/Sep/27 at www.scientific.net (C (2013) Trans Tech Publications, Switzerland doi:10.4028/www.scientific.net/AMM.420.68 ISSN: 1660-9336.

[15] ZMINDAK, M., RADZISZEWSKI, L., PELAGIC, Z., FALAT, M.: Fem/bem Techniques for Modelling of Local Fields in Contact Mechanics. Communications - Scientific Letters of the University of Zilina, vol. 17, No. 3, 2015, pp. 37-46.

[16] SAGA, M., VASKO, M., KOPAS, P., JAKUBOVICOVA, L.: Numerical Algorithm for Beam Residual Stress Identification. Communications - scientific letters of the University of Zilina, vol. 16, No. 3A, 2014, pp. 13-18, ISSN 1335-4205.

[17] KOPAS, P., SAGA, M.: In-phase Multiaxial Fatigue Experimental Analysis of Welded Cylindrical 6063-T66 Aluminium Alloy Specimens. Manufacturing Technology, vol.13, No. 1, 2013, pp. 59-64, ISSN 1213-2489. 